Cybernetics: Journal Educational Research and Social Studies

Volume 2, Nomor 4, Oktober 2021

Journal Homepage: http://pusdikra-publishing.com/index.php/jrss

\title{
Pengaruh Model Make A Match Berbantu Kartu Bergambar Terhadap Hasil Belajar IPS Tema Kayanya Negeriku Di Kelas IV SDN No 105361 Lubuk Cemara
}

\author{
Cindy Pratiwi ${ }^{1}$, Umar Darwis ${ }^{2}$ \\ 1,2 Universitas Muslim Nusantara Al-Washliyah
}

Corresponding Author : cindypratiwi456@gmail.com

\section{ABSTRACT}

\begin{abstract}
This study aims to determine the results of social studies learning using a make a match model with the help of picture cards. This is shown from the results of the calculation of the posttest hypothesis test through the t-test at a significance level of 0.05 , where tcount $>$ ttable $(4.25>1.994437)$ This result is strengthened by the achievement of the average score of students in the conventional learning class with the value of 76.2 while the make a match model obtained a value of 88.97 . These results indicate that student activities can be categorized very well in using the make a match model with the help of picture cards.
\end{abstract}

Kata Kunci Model Make A Match, Hasil Belajar, IPS

\section{PENDAHULUAN}

Pendidikan adalah suatu proses untuk membantu manusia dalam mengembangkan diri baik nilai dan budaya dan meningkatkan harkat serta martabat manusia, sehingga manusia siap menghadapi setiap perubahan yang terjadi menuju ke arah yang lebih baik. Peserta didik yang mengikuti pendidikan masa kini akan menggunakan apa yang diperolehnya dari pendidikan dalam kehidupannya di masa depan. Oleh karena itu proses pendidikan perlu diarahkan agar memberi kemampuan bagi peserta didik yang bermanfaat bagi kehidupannya di masa depan terutama masa dimana dia telah menyelesaikan semua jenjang pendidikan formalnya. Dengan demikian, pembentukan kepribadian, keterampilan dan perkembangan intelektual siswa yang menjadi konten pendidikan harus dapat digunakan dalam kehidupan sebagai pribadi, anggota keluarga, masyarakat, dan warga negara yang produktif serta bertanggung jawab di kemudian hari.

Salah satu masalah yang dihadapi dunia pendidikan di Indonesia adalah masalah lemahnya proses pembelajaran. Dalam proses pembelajaran anak kurang didukung untuk mengembangkan kemampuan berpikir. Proses belajar pembelajaran dikelas diarahkan pada kemampuan anak untuk menghafal informasi, otak anak dipaksa untuk mengingat dan menimbun berbagai informasi tanpa memahami informasi tersebut tetapi dituntut untuk menerapkan nya pada kehidupan sehari-hari. Pendidikan dapat dikatakan suatu 
proses yang sadar akan tujuan. Tujuan di artikan sebagai suatu usaha untuk memberikan rumusan hasil yang diharapkan siswa setelah melaksanakan pengalaman belajar. Pengalaman belajar bisa didapat dari mana saja, salah satu nya disekolah, mata pelajaran IPS merupakan salah satu mata pelajaran yang diajarkan disekolah. Ilmu pengetahuan sosial merupakan kajian integrasi dari berbagai cabang ilmu-ilmu sosial. Materi IPS di desain sesecara terpadu agar pembelajaran IPS lebih bermakna dan kontekstual. IPS juga menelaah masalah masalah sosial kemasyarakatan dan kebangsaan, seiring dengan perkembangan ilmu pengetahuan dan teknologi, serta tuntutan dunia global Supardi (2011: 182). Tujuan utama Ilmu pengetahuan sosial ialah untuk mengembangkan potensi peserta didik agar peka terhasap masalah sosial yang terjadi di masyarakat, memiliki sikap mental positif terhadap prbaikan segala ketimpangan yang terjadi dan terampil mengatasi setiap masalah yang terjadi sehari-hari, baik yang menimpa dirinya sendiri maupun yang menimpa masyarakat.

Salah satu upaya pemerintah dalam meningkatkan mutu pendidikan yaitu dengan memperbaiki kurikulum. Kurikulum yang dibutuhkan yaitu mengembangkan kemampuan siswa baik ranah kognitif, afektif, maupun psikomotorik, oleh karena itu Kurikulum Tingkat Satuan Pendidikan (KTSP) disempurnakan menjadi kurikulum 2013 yang memiliki tujuan untuk mempersiapkan manusia Indonesia agar memiliki kemampuan hidup sebagai manusia yang beriman, produktif, kreatif, inovatif dan afektif serta mampu berkontribusi pada kehidupan masyarakat berbangsa, bernegara, dan peradaban dunia (Kemendikbud, 2013).

Sesuai dengan kurikulum 2013 yang diterapkan pada pembelajar dikelas IV SD terdapat 9 tema yang harus dipelajari siswa diantara nya adalah Tema 9 kayanya negeriku adapun pembahasan yang terdapat didalam Tema 9 yaitu mengaitkan 4 subtema diantaranya yaitu subtema 1 kekayaan sumber energi di Indonesia, subtema 2 pemanfaatan kekayaan alam di Indonesia, subtema 3 pelestarian sumber daya alam Indonesia subtema 4 kayanya prestasiku (project based learning). Subtema 1 kekayaan sumber energi di Indonesia merupakan subtema yang penting dipahami oleh siswa dikarenakan isi dari subtema 1 yaitu membahas mengenai kegiatan ekonomi masyarakat berdasarkan sumber daya alam dilingkungan nya. Indonesia memiliki kekayaan sumber daya alam sehingga peserta didik hendak nya tahu mengenai berbagai sumber daya alam yang ada di Indonesia. Terlebih lagi sumber daya alam yang ada dilingkungan nya.

Pada hasil wawancara dengan guru kelas IV tanggal 22 Februari 2021 di SDN No 105361 Lubuk Cemara di masa pandemi guru menerapkan sistem belajar luring atau luar jaringan. Proses belajar siswa tetap dilakukan seperti 
biasa tetapi tidak di lingkungan sekolah. Hal ini mengakibatkan menurun nya semangat siswa untuk belajar, belajar diluar lingkungan sekolah terasa membosankan dan terasa seperti tidak sekolah tentu ini sulitnya guru untuk menerapkan berbagai materi pembelajaran. Sebagian guru telah menerapkan pembelajaran menggunakan media berupa gambar yang terdapat didalam buku pelajaran siswa, tetapi hal ini membuat pelajaran menjadi membosan kan dan tidak mudah di ingat oleh siswa. Pada dasarnya siswa lebih mengingat sesuatu yang ia lihat dan alami daripada hanya mendengar dan membayangkan saja. Namun sangat di sayangkan karena kenyataan di lapangan bahwa masih banyak yang beranggapan pelajaran IPS kurang memiliki kegunaan yang besar bagi siswa dibandingkan dengan pendidikan IPA dan Matematika yang mengkaji bidang pengembangan sains dan teknologi. Tentu anggapan tersebut kurang tepat karena disadari bahwa pendidikan IPS dikembangkan dalam rangka meningkatkan kualitas sumber daya manusia dibidang nilai dan sikap, pengetahuan serta dunia nyata, khusus nya kehidupan sosial di masyarakat pada umumnya. Mewujudkan pembelajaran IPS yang diharapkan tidaklah mudah. Terbukti masih kerap ditemui hasil belajar IPS siswa yang cenderung rendah dilapangan. Hal tersebut menandakan bahwa beberapa tempat, pembelaharan IPS yang diharapkan belum dapat terwujud dengan maksimal.

Masih banyak guru yang mementingkan aspek kognitif saja dan kurang memandang dari segi minat dan ketertarikan lebih oleh siswa dalam belajar. Terutama dalam pelajaran IPS pada Tema Kayanya Negeriku Kurangnya motivasi siswa dalam belajar tentunya menjadikan siswa memiliki nilai yang rendah. Sangat di khawatirkan siswa menjadi tidak tertarik terhadap pelajaran IPS. Pelajaran kegiatan ekonomi berdasarkan sumber daya alam nya yang dibahas didalam Tema kayanya negeriku apabila hal ini dijadikan hal yang tidak serius siswa akan memiliki kekurangan pengetahuan mengenai berbagai sumber daya alam yang luar baisa banyak di Indonesia. Hal ini perlu didalami oleh siswa dimulai sedari sekolah dasar mengenai kegiatan ekonomi berdasarkan sumber daya alam nya demi kelangsungan hidup yang lebih baik di kehidupan nya dimasa depan dengan memanfaatkan sumber daya alam disekitarnya agar dapat di kelola dengan baik.

Adapun permasalahan yang terjadi pada SDN No 105361 Lubuk Cemara terkait dengan pelajaran yang memiliki nilai rendah yaitu mata pelajaran IPS. Mata pelajaran IPS menjadi pelajaran yang kerap kali tidak diminati oleh siswa yang menyebabkan siswa memiliki nilai yang rendah dan tidak mencukupi KKM. Pernyataan tersebut didukung dengan hasil nilai UTS siswa kelas IV SDN No 105361 Lubuk cemara pada mata pelajaran IPS. 
Cybernetics: Journal of Research and Educational Studies

Volume 2 Nomor 4, Oktober 2021

Halaman 114-122

Tabel 1.

Data Siswa Kelas IV SDN No 105361 Lubuk Cemara

\begin{tabular}{|c|c|c|c|c|c|}
\hline No & Kelas & $\begin{array}{c}\text { KKM } \\
\text { IPS }\end{array}$ & $\begin{array}{c}\text { Jumlah } \\
\text { siswa }\end{array}$ & $\begin{array}{c}\text { Mencapai } \\
\text { ketuntasan } \\
\text { KKM }\end{array}$ & $\begin{array}{c}\text { Tidak mencapai } \\
\text { ketuntasan KKM }\end{array}$ \\
\hline 1. & IV A & 70 & 34 & $26 \%$ & $73 \%$ \\
\hline 2. & IV B & 70 & 34 & $29 \%$ & $71 \%$ \\
\hline
\end{tabular}

Berdasarkan tabel di atas peneliti akan mencoba untuk melakukan eksperimen pada kelas IV SDN No 105361 Lubuk Cemara yang bertujuan untuk mengetahui model pembelajaran yang dapat meningkatkan hasil belajar terutama pada mata pelajaran IPS. Salah satu model pembelajaran yang dapat digunakan yaitu model pembelajaran make a match. Model pembelajaran make a match merupakan model pembelajaran yang dikembangkan Loma Curran, ciri utama model make a match adalah siswa di minta mencari pasangan kartu yang merupakan jawaban atau pertanyaan materi tertentu dalam pembelajaran. Keunggulan teknik ini adalah siswa mencari pasangan sambil belajar mengenai suatu konsep atau topik dalam suasana yang menyenangkan. Tenik ini bisa digunakan dalam semua mata pelajaran dan untuk semua tingkatan usia (Isjini, 2010: 78) Karakteristik model make a match adalah memiliki hubungan yang erat dengan siswa yang gemar bermain dan sangat cocok diterapkan pada siswa sekolah dasar.

Oleh karena itu, alasan pemilihan model pembelajaran make a match merupakan rangkaian penyampaian materi dengan menggunakan cara memasangkan sebagai wadah dalam menyatukan persepsi/ pikiran siswa terhadap pertanyaan yang terdapat pada kartu bergambar dengan jawaban yang cocok menggunakan kartu yang ia dapatkan dari guru. Dengan demikian, siswa akan lebih berfikir untuk mencari jawaban dari pertanyaan dengan cara yang menyenangkan.

Ketika peserta didik belajar dengan aktif berarti mereka yang mendominasi aktivitas pembelajaran. Mereka secara aktif menggunakan otak baik untuk menemukan ide pokok dari materi pelajaran dan memecahkan persoalan. Jadi pembelajaran dengan model make a match adalah suatu model pembelajaran yang membuat siswa menjadi aktif, siswa diajak untuk menyelesaikan masalah dengan menggunakan pengetahuan yang mereka miliki dan menerapkan apa yang mereka pelajari.

Dari paparan tersebut, maka penulis ingin melakukan penelitian lebih mendalam dengan memilih judul "Pengaruh model make a match berbantu kartu 
Cybernetics: Journal of Research and Educational Studies

Volume 2 Nomor 4, Oktober 2021

Halaman 114-122

bergambar terhadap hasil belajar IPS tema kayanya negeriku di kelas IV SDN No 105361 Lubuk Cemara".

\section{METODE PENELITIAN}

Desain penelitian ini menggunakan pendekatan deskriptif kuantitatif bertujuan untuk mengetahui hubungan antara dua variable atau lebih (winarno 2013:67). Penelitian kuantitatif memandang tingkah laku manusia dapat diramal dan realitas sosial objektif dandapat diukur. Pendekatan kuantitatif menggunakan rancangan yang terstruktur, formal, dan spesifik. Data yang dikumpulkan sebelum turun ke lapangan jenis data yang dikumpulkan merupakan data kuantitatif yang lebih banyak angka bukan kata-kata atau gambar. Disamping itu dapat juga dilakukan dengan "sekali pukul dan selesai" serta tidak diperlukan peneliti untuk selamanya melakukan observasi pada objek yang sedang diteliti. Penelitian ini menggunakan jenis penelitian Quasi Experimental dengan desain Two-group Post-Test-Only Design.

Penelitian ini membahas tentang pengaruh model make a match berbantu kartu bergambar terhadap hasil belajar IPS Tema Kayanya Negeriku Kelas IV SDN No 105361 Lubuk Cemara. Penelitian ini menggunakan penelitian Eksperimen Semu dengan menggunakan desain Two-group Post-Test-Only Design.

\section{HASIL PENELITIAN DAN PEMBAHASAN}

Perbandingan Data Statistik Kelompok Kelompok Model Make A Match Dan Pembelajaran Konvensional

Data statistik memudahkan peneliti dalam perhitungan uji prasyarat dan uji hipotesis nantinya. Data statistik posttest mengenai kedua kelompok berdasarkan perhitungan, sebagai berikut:

Tabel 2.

Data Statistik Hasil Penelitian Posttest

\begin{tabular}{|c|c|c|}
\hline \multirow{2}{*}{ Data Statistik } & \multicolumn{2}{|c|}{ Posttest } \\
\cline { 2 - 3 } & Model Make a match & $\begin{array}{l}\text { Pembelajaran } \\
\text { Konvensional }\end{array}$ \\
\hline Nilai Tertinggi & 97,5 & 85 \\
\hline Nilai Terendah & 73,5 & 52,5 \\
\hline Rata-Rata & 88,97 & 76,2 \\
\hline Median & 81,38 & 70,3 \\
\hline Modus & 96,125 & 77,9 \\
\hline Jumlah Siswa & 34 & 34 \\
\hline
\end{tabular}


Tabel di atas memperlihatkan hasil posttest kedua kelompok penelitian yang menunjukkan perbedaan. Nilai maksimum dan nilai minimum posttest yang diperoleh kelompok model make a match dan kelompok pembelajaran konvensional menunjukkan perbedaan yaitu nilai maksimum 97,5 dan 85 sedangkan nilai minimum 73,5 dan 52,5 . Selain itu, nilai rata-rata kedua kelompok juga menunjukkan perbedaan yaitu 88 ,

97 untuk nilai rata-rata kelompok model make a match dan 76,2 untuk nilai rata-rata kelompok pembelajaran konvensional dan selisih nilai rata-rata kedua kelompok ialah sebesar 12,77. Hasil ini menunjukkan bahwa perolehan nilai posttest kelompok model make a match lebih tinggi dari pada kelompok pembelajaran konvensional.

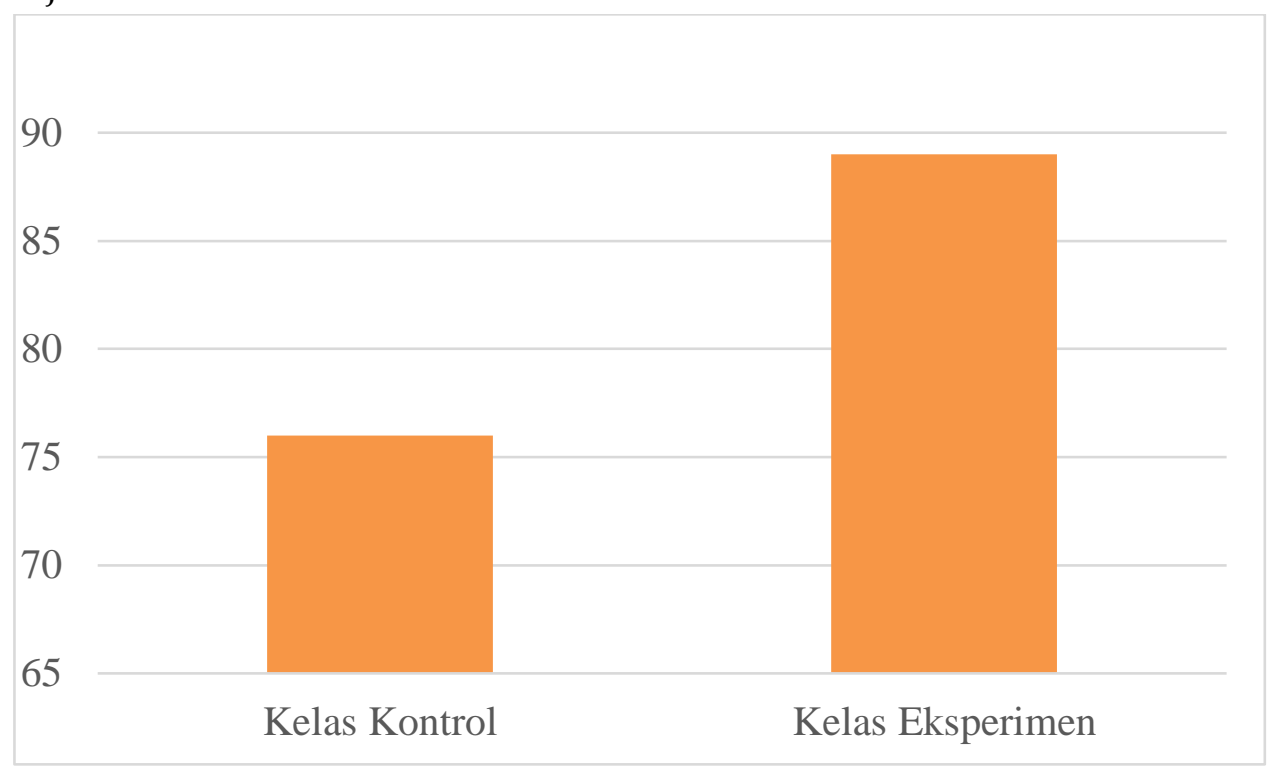

\section{Gambar 1. \\ Diagram Batang Perbandingan Data Statistik Kelompok Model Make A Match Dan Pembelajaran Konvensional}

\section{Pembahasan}

Berdasarkan hasil uji hipotesis penelitian ini menemukan bahwa hasil belajar siswa menggunakan model Make A Match berbantu kartu bergambar secara umum mengalami perbedaaan yang signifikan. Namun, pada kelas Model make a match hasil belajar siswa lebih tinggi dibandingkan kelas pembelajaran konvensional. Hal ini dikarenakan ada perbedaan perlakuan yang diberikan kepada kedua kelompok. Siswa yang diajarkan menggunakan model pembelajaran make a match akan lebih berfikir untuk mencari jawaban dari pertanyaan dengan cara yang menyenangkan.

Kelas dengan pembelajaran model make a match ini sangat bermanfaat dalam mencapai tujuan pembelajaran. Model make a match ini memiliki 
Cybernetics: Journal of Research and Educational Studies

Volume 2 Nomor 4, Oktober 2021

Halaman 114-122

kelebihan yaitu suasana kegembiraan akan tumbuh dalam proses pembelajaran, kerjasama sama antar sesame terwujud dengan dinamis, serta Munculnya dinamika gotong royong yang merata diseluruh siswa (Aris Shoimin 2016:99).

Kelas IVA diajarkan menggunakan Pembelajaran Konvensional dengan tahap menurut Syahrul (dalam Ibrahim,2017:202) bahwa tahap- tahap penggunaan Pembelajaran Konvensional yaitu: “1) menyampaikan tujuan, 2) menyampaikan informasi, 3) mengecek pemahaman dan memberi umpan balik, dan 4) memberikan latihan lanjutan".

Sebelum diberikan perlakuan, kedua kelas diuji normal dan homogennya untuk memilih kelas Model make a match dan kelas Pembelajaran konvensional. Setelah diuji kedua kelas normal dan homogen, didapatkan kedua kelas normal dan homogen. Maka dipilih kelas menggunakan kelas Model make a match dan Pembelajaran konvensional dengan ketentuan kelas yang menggunakan Model make a match memiliki rata-rata hasil belajar yang tinggi dari kelas yang menggunakan pembelajaran konvensional.

Kedua kelas diberikan perlakuan dengan Model make a match dan Pembelajaran konvensional. Kelas IVB diajarkan menggunakan Model make a match dengan langkah yaitu:

1. Guru mempersiapkan beberapa kartu yang berisi beberapa konsep atau topik yang cocok untuk sesi review, sebaliknya satu bagian kartusoal dan bagian lain nya kartu jawaban.

2. Setiap siswa mendapat satu buah kartu.

3. Setiap siswa memikirkan jawaban/soal dari kertu yang dipegang

4. Setiap siswa mencari pasangan yang mempunyai kartu yang cocok dengan kartunya (soal jawaban)

5. Setiap siswa yang dapat mencocokan kartunya sebelum batas waktu diberi point. (Aris Shoimin 2016: 98-99)

Kedua kelas diberikan posttest, siswa yang menggunakan Model make a match lebih aktif dibanding dengan kelas Pembelajaran konvensional. Hal ini didukung oleh data yang tertera pada lampiran 19. yang menunjukkan jumlah rata-rata kelas Model make a match lebih tinggi dibanding dengan jumlah ratarata kelas Pembelajaran konvensional. Rata-rata nilai kelas Model make a match lebih besar yaitu 88,97 daripada rata-rata nilai pada kelas Pembelajaran konvensional yaitu 76,2. Hal ini menunjukan terdapat pengaruh yang signifikan menggunakan model make a match berbantu kartu bergambar terhadap hasil belajar IPS.

Hal tersebut sesuai dengan hasil uji-t, dimana pada perhitungan uji-t skor posttest menunjukkan bahwa terdapat perbedaan yang signifikan. Skor posttest kelas yang menggunakan Pembelajaran konvensional dan kelas yang 
Cybernetics: Journal of Research and Educational Studies

Volume 2 Nomor 4, Oktober 2021

Halaman 114-122

menggunakan Model make a match dimana nilai thitung lebih besar dari t tabel $(4,25>1,994437)$.

Dengan demikian dapat dinyatakan bahwa terdapat perbedaan yang signifikan pada hasil belajar yang diajarkan dengan Pembelajaran konvensional dengan hasil belajar yang diajarkan dengan Model make a match , dimana hasil belajar kelompok yang menggunakan Model make a match lebih baik dari pada kelompok yang menggunakan Model pembelajaran konvensional.

\section{KESIMPULAN}

Berdasarkan hasil analisis data dapat disimpulkan bahwa terdapat pengaruh yang signifikan terhadap hasil belajar IPS menggunakan model make a match berbantu kartu bergambar. Hal ini ditunjukkan dari perolehan hasil perhitungan uji hipotesis posttest melalui uji-t pada taraf signifikansi 0,05, dimana $t_{\text {hitung }}>t_{\text {tabel }}$ yaitu $(4,25>1,994437)$ Hasil ini diperkuat dengan pencapaian rata-rata nilai siswa pada kelas Pembelajaran konvensional dengan nilai 76,2 sedangkan Model make a match memperoleh nilai 88,97 Hasil ini menunjukkan bahwa aktivitas kegiatan siswa dapat dikategorikan sangat baik dalam menggunakan model make a match berbantu kartu bergambar.

\section{REFERENCE}

A.Muri Yusuf, (2014) Metode penelitian kuantitatif, kualitatif, dan penelitian gabungan Jakarta: Prenadamedia Group

Anggrawati Ary (2014) jurnal pengaruh model make a match berbantuan kartu gambar terhadap hasil belajar IPS Vol :2 No: 1

Alma Buchari (2004) Belajar mudah penelitian. Bandung :Alfabeta

Arikunto, Suharsimi. (2007). Manajemen Penelitian. Jakarta: Rineka Cipta.

Arikunto, Suharsimi. (2012). Dasar-dasar Evaluasi Pendidikan. Yogyakarta: Bumi Aksara.

Aris shoimin (2014) 68 model Pembelajaran Inovatif dalam Kurikulum 2013 Yogyakarta: Ar-Ruzz Media

Agus Irianto (2004) Statistik. Padang: Kencana Prenada Media Group

Gultom, T. (2020). Penilaian Kinerja Guru Mengenai Profesionalisme Guru Di Smp Negeri 2 Pangaribuan Kabupaten Tapanuli Utara Tahun 2020. Journal Of Education And Teaching Learning (JETL), 2(3), 29-43. https://doi.org/10.51178/jetl.v2i3.66

Hasan Said Hamid. (1996) Pendidikan Ilmu sosial. Jakarta: Dirjendikti, Depdikbud RI

Ibrahim, \& Suparni. (2012). Pembelajaran Matematika Teori dan Aplikasinya. Yogyakarta: SUKA-Press UIN Sunan Kalijaga. 
Cybernetics: Journal of Research and Educational Studies

Volume 2 Nomor 4, Oktober 2021

Halaman 114-122

Istirani \& Intan pulungan (2020) Ensiklopedi Pendidikan .Medan : Larispa

Imas Kurbiasih dan Berlian Sani (2015) Ragam Pengembangan Model Pembelajaran, Kata Pena

Lestari, Karunia Eka dan M. Ridwan. (2015).Penelitian Pendidikan Matematika. Bandung: PT Refika Aditama

Majid, Abdul. 2014. Strategi Pembelajaran. Bandung: Remaja Rosdakarya.

Muamar Al Qadri, S. W. (2021). Pengaruh Home Visit Method Terhadap Hasil Belajar Luring di Masa Pandemi COVID-19 Pada Mata Pelajaran Al Qur'an Hadits (Studi Kasus Siswa Kelas VIII MTS Jam'iyah Mahmudiyah Tanjung Pura Langkat). Continuous Education: Journal of Science and Research, 2(1), 6171. https://doi.org/10.51178/ce.v2i1.187

Rif'at. (2017). Instrumen Penelitian Yang Valid dan Reliabel. Jurnal Edukasi Sebelas April. Vol. 1 No.1

Sugiyono (2018) metode penelitian kuantitatif kualitatif \& RED. Yogyakarta: Alfabeta

Susanto, Ahmad. (2015). Teori Belajar dan Pembelajaran di Sekolah Dasar. Jakarta: Kencana.

Sofan Amri, (2013) pengembangan \& model pembelajaran dalam kurikulum 2013. Jakarta: Prestasi pustaka publisher

Siti Dewi Fatimah, (2018) Pengembangan APE kartu pasangan pada tema Indanya keragaman di negeriku subtema indahya keragaman budaya negeriku untuk siswa kelas IV, Jember

Siti Rodi'ah, I. H. (2021). Strategi Pembelajaran Pendidikan Jasmani Berbantu Media Book Creator Digital Dalam Meningkatkan Kemampuan Motorik Kasar Siswa Pada Tingkat Sekolah Dasar. Continuous Education: Journal of Science and Research, 2(2), 23-35. https://doi.org/10.51178/ce.v2i2.225

Suryosubroto, B. 2009. Proses Belajar Mengajar di Sekolah. PT Rineka Cipta. Jakarta. Triyanto. 2011. Desain Pengembangan Pembelajaran Tematik Bagi Anak Usia Dini TK/RA \& Anak Usia Kelas Awal SD/MI. Kencana Prenada Media Group. Jakarta. 